Research Report 1701

\title{
Relationship Between Platoon Gunnery Training and Live-Fire Performance
}

\author{
Bruce S. Sterling \\ U.S. Army Research Institute
}

\section{Armored Forces Research Unit Barbara A. Black, Chief}

\author{
U.S. Army Research Institute for the Behavioral and Social Sciences \\ 5001 Eisenhower Avenue, Alexandria, Virginia 22333-5600 \\ Office, Deputy Chief of Staff for Personnel \\ Department of the Army \\ September 1996
}

